\title{
Lautignac et Savères
}

Ruisseau de la Saverette

\section{Gilles Peyre}

\section{(2) OpenEdition}

1 Journals

Édition électronique

URL : http://journals.openedition.org/adlfi/11087

ISSN : 2114-0502

Éditeur

Ministère de la culture

Référence électronique

Gilles Peyre, "Lautignac et Savères », ADLFI. Archéologie de la France - Informations [En ligne], Midi-

Pyrénées, mis en ligne le 01 mars 1997, consulté le 03 mai 2019. URL : http://

journals.openedition.org/adlfi/11087

Ce document a été généré automatiquement le 3 mai 2019.

(c) Ministère de la Culture et de la Communication, CNRS 


\title{
Lautignac et Savères
}

\author{
Ruisseau de la Saverette
}

\section{Gilles Peyre}

Date de l'opération : 1990 (SD)

Inventeur(s) : Peyre Gilles

1 Le projet de création d'un réservoir d'eau a été à l'origine d'une opération de prospection-sondage motivée par la présence d'un établissement gallo-romain de forte étendue, situé entre le cimetière de Savères et la rive droite du ruisseau (Gallia, 1974, p.469-470).

2 Des prospections aériennes et des prospections au sol s'étant avérées négatives, plusieurs sondages mécaniques effectués au lieu-dit Pradas ont confirmé l'existence d'un établissement gallo-romain dont la partie menacée correspondait à des structures légères, sans doute comprises dans la pars rustica d'une villa.

3 La couche de destruction décelée à plusieurs endroits (crépis, briques, céramiques communes et sigillées Drag. 19, 35/36, 37) semble devoir confirmer l'occupation flavienne de ce bâtiment agricole.

4 Quelques céramiques attribuables aux $\mathrm{X}^{\mathrm{e}} \mathrm{s}$. et $\mathrm{XI}^{\mathrm{e}} \mathrm{s}$. attestent la pérennité de l'occupation mais sans que l'on puisse en préciser la nature.

INDEX

Index chronologique : Antiquité romaine

operation sondage (SD) 